\title{
Patterns and Correlates of Expressed Emotion, Perceived Criticism, and Rearing Style in First Admitted Early-Onset Schizophrenia Spectrum Disorders
}

\author{
Georg G. von Polier, MD, * Heiner Meng, MD, $\dagger$ Martin Lambert, MD, $\neq$ Monika Strauss, MD, $\S$ \\ Gianni Zarotti, MD, PhD, II Michael Karle, MD, Dipl.Psych, $\mid$ Reinmar Dubois, MD,\# Fritz-Michael Stark, MD, ** \\ Sibylle Neidhart, Lic. Phil, †† Ruedi Zollinger, MD, § Dieter Bürgin, MD, † Wilhelm Felder, MD, Il Franz Resch, MD, †f \\ Eginhard Koch, MD, + Michael Schulte-Markwort, MD, $\S \S$ and Benno G. Schimmelmann, MDIl
}

\begin{abstract}
The aim of this study was to assess patterns and correlates of family variables in 31 adolescents treated for their first episode of a schizophrenia spectrum disorder (early-onset schizophrenia [EOS]). Expressed emotion, perceived criticism, and rearing style were assessed. Potential correlates were patient psychopathology, premorbid adjustment, illness duration, quality of life (QoL), sociodemographic variables, patient and caregiver "illness concept," and caregiver personality traits and support. Families were rated as critical more frequently by patients than raters $(55 \%$ vs. $13 \%)$. Perceived criticism was associated with worse QoL in relationship with parents and peers. An adverse rearing style was associated with a negative illness concept in patients, particularly with less trust in their physician. Future research should examine perceived criticism as a predictor of relapse and indicator of adolescents with EOS who need extended support and treatment. Rearing style should be carefully observed because of its link with patients' illness concept and, potentially, to service engagement and medication adherence.
\end{abstract}

Key Words: Family, psychosis, adolescents, expressed emotion, perceived criticism, parental bonding

(J Nerv Ment Dis 2014;202: 00-00)

$\mathrm{E}$ arly-onset schizophrenia spectrum disorders (age of onset < - 18 years; henceforth EOS) are associated with many negative outcomes, including worse premorbid functioning, longer duration of untreated psychosis (DUP), a higher number of negative symptoms at initial presentation, and lower response rates to and more side effects with antipsychotic treatment (Meng et al., 2006; Schimmelmann et al., 2007, 2013a). Furthermore, EOS seems to have distinguishable prodromal features (Fux et al., 2013; Schimmelmann et al., 2011, 2013b). These findings highlight the importance of identifying malleable prognostic factors in EOS.

\footnotetext{
*Department of Child and Adolescent Psychiatry, RWTH Aachen University, Aachen, Germany; $\dagger$ Department of Child and Adolescent Psychiatry, University of Basel, Basel, Switzerland; \$Psychosis Centre, Department of Psychiatry, University Hospital Hamburg-Eppendorf, Hamburg, Germany; §Department of Child and Adolescent Psychiatry, St Gallen, Switzerland; ॥University Hospital of Child and Adolescent Psychiatry, University of Bern, Bern, Switzerland; qDepartment of Child and Adolescent Psychiatry, University of Tuebingen, Tuebingen, Germany; \#Department of Child and Adolescent Psychiatry, Olgahospital, Stuttgart, Germany; **Department of Psychiatry, Asklepios Clinical Center West, Hamburg, Germany; † Center for Family Counceling and School Psychology, Allschwil/Basel, Switzerland; \$tDepartment of Child and Adolescent Psychiatry, University of Heidelberg, Heidelberg, Germany; and §§Department of Child and Adolescent Psychiatry, University Hospital Hamburg-Eppendorf, Hamburg, Germany.

Send reprint requests to Georg G. von Polier, MD, Department for Child and Adolescent Psychiatry, Psychosomatics and Psychotherapy, RWTH Aachen University, Neuenhofer Weg 21, 52074 Aachen, Germany. E-mail: gvonpolier@ukaachen.de.

Copyright (C) 2014 by Lippincott Williams \& Wilkins

ISSN: 0022-3018/14/20211-0000

DOI: $10.1097 / \mathrm{NMD} .0000000000000209$
}

In adults with schizophrenia, family environment and, to a certain degree, rearing style (i.e., parental bonding; Parker et al., 1988) are important predictors of treatment course. In particular, a link has been established between an adverse family climate (defined as high expressed emotion [HEE] status) and a markedly increased relapse rate and higher risk for a chronic course of illness (Butzlaff and Hooley, 1998; Cechnicki et al., 2013). Although both an EE status and rearing style describe a possibly stressful or supportive environment of patients within their families, both measures seem to be associated only weakly and, therefore, represent separate paradigms of family environment (Parker et al., 1988). Family interventions have proven to effectively decrease the frequency of relapse, hospital admissions, and medication nonadherence as well as to reduce HEE (Pharoah et al., 2010). However, studies looking at firstepisode psychosis have been more ambiguous in their recommendations, and some have questioned the long-term efficacy or even reported potential harmful effects of family interventions with families that intuitively cope well (Bird et al., 2010; Linszen et al., 2001, 1996). Hence, it is necessary to understand which families benefit from family interventions to develop more tailored treatment approaches (Onwumere et al., 2011).

Small-scale studies conducted with patients with EOS provide support for a link between adverse family climate (i.e., HEE status) at admission and an increased relapse rate after 1 and 2 years (Jarbin et al., 2000). Given that adolescents with schizophrenia are often highly affected by family interaction and conflicts related to the process of age-appropriate detachment, it is surprising that little is known about family variables in EOS and that age-appropriate family interventions have not been designed to date (Algon et al., 2012; Gearing, 2008). Against this background, the aim of this cross-sectional study is to explore family variables (e.g., caregiver EE, rearing style, and patientperceived criticism) and their relationship with relevant patient and caregiver characteristics in adolescents experiencing their first episode of a schizophrenia spectrum disorder. These correlates should provide information about potential clinical and research strategies to improve family interventions in this population.

\section{METHODS}

\section{Participants}

Participants included adolescents with a schizophrenia spectrum disorder receiving their first treatment of psychosis in one of the seven adolescent psychiatric sites in Switzerland and Germany (VESPA group) (Meng et al., 2009) They were enrolled based on the following inclusion criteria: age of 14 to 18 years, antipsychotic treatment of 4 weeks or less, and living with a parent or guardian for at least 3 months before admission. Forty-two adolescents fulfilled the inclusion criteria. Eleven refused to participate in family assessments, leaving 31 participants who enrolled in the study. Of these, 29 participants were receiving inpatient treatment, and two were outpatients. The 11 adolescents who did not participate did not differ significantly from the study sample regarding illness severity, age, or sex. 


\section{Assessments \\ Patient Variables}

The following are the patient variables: a) premorbid functioning, assessed using the Premorbid Adjustment Scale (PAS, higher scores indicate poorer premorbid functioning) (Cannon-Spoor et al., 1982; Krauss et al., 2000); b) number of life events in the past 12 months with the Zurich life event list (Steinhausen and Winkler Metzke, 2001); c) DUP and duration of untreated illness (DUI) as well as duration of untreated negative symptoms (DUN) with the Symptom Onset in Schizophrenia inventory (Perkins et al., 2000); d) Diagnostic and Statistical Manual of Mental Disorders, Fourth Edition (DSM-IV) diagnosis of schizophrenia spectrum disorders and international statistical classification of diseases and related health problems diagnosis of substance use disorder by clinical interviews (American Psychiatric Association, 2000; Dilling and Huber, 2008); e) the Positive and Negative Syndrome Scale (PANSS) (Bunk et al., 1999; Kay et al., 1987); f) the Clinical Global Impressions-Severity of Illness Scale (CGI-S) (Guy, 1976); g) adolescent behavior as rated by parents with the Child-Behaviour Checklist (Achenbach, 1991; Döpfner et al., 1994); h) quality of life with the parent-completed Inventory of Children's Quality of Life (ILK), which covers school performance, interaction with family, peer group relations, physical health, mental health, and overall quality of life (Mattejat et al., 1998); i) illnessrelated and therapy-related caregivers' burden with the ILK; j) "illness concept" with the Illness Concept Scale (Linden et al., 1988); and k) early course of treatment with CGI-I (improvement) after 2 weeks of treatment.

\section{Family Variables}

a) EE was assessed with the Five Minutes Speech Sample (FMSS) (Leeb et al., 1991; Magana et al., 1986; Stark and Buchkremer, 1992). Speech samples were rated by external experts with established interrater reliability (authors M. S. and S. N.). Caregivers were rated as low EE (LEE) or HEE on the dimensions of criticism and emotional overinvolvement (EOI). A family was rated HEE if one or both caregivers were rated HEE. b) Perceived criticism was assessed with a 5-point Likert scale completed by adolescents to independently rate their mother's and father's criticism during the last 4 weeks (Hooley and Teasdale, 1989). Caregivers were rated "perceived critical" if ratings were medium and higher. c) Perceived rearing style was examined with the Parental Bonding Instrument (PBI, perceived by the adolescent), assessing caregiver care and protection. Families were grouped into "optimal parenting" (high care, low protection) and "affectionless control" (high protection, low care) (Parker et al., 1979).

\section{Parents or Caregivers}

a) Personality traits were examined with the Hamburg Personality Inventory (Andresen, 2000). b) The rater estimated the mother's and father's lack of acceptance/support of the patient on a one-item 5-point Likert scale (high scores indicate low acceptance/support). c) Illness concept was assessed with the Illness Concept Scale (Linden et al., 1988).

\section{Procedure}

For 14 adolescents, both parents participated in the study; for 15 adolescents, only one parent participated in the study; and for 2 adolescents who were in out-of-home placement, one significant attachment figure each participated. To limit the influence of treatment, assessment of perceived criticism, illness concept, psychopathology, severity of illness, and global functioning were completed within 2 weeks of the start of treatment. Other variables, including diagnoses, duration of illness, perceived rearing style, and past life events, were assessed within the first 3 months, after clinical stabilization. Raters of correlates were blinded to family variables and vice versa. Written informed consent was obtained from participants and their legal guardians. All local research ethics committees approved the study. Study monitoring and data processing were performed by one site (authors G. G. P. and B. G. S.). Raters were trained extensively by authorized trainers in the application of assessment scales before and during the course of the study (particularly on the FMSS, PANSS, and diagnostic DSM-IV research criteria interviews). Problems with assessments were discussed individually on a helpline or at regular follow-up meetings twice a year. This procedure assured data quality and minimized missing or incomplete data. Interrater reliability of the PANSS total score was high $(\kappa=0.84)$.

\section{Data Analysis}

Descriptive statistics were calculated as means, standard deviations, frequency counts, and percentages. The normality of the continuous predictor variables was determined using Kolmogorov-Smirnov tests. DUP, DUN, and DUI were significantly positively skewed, so their data were normalized with logarithmic transformation. To explore relationships between family variables and patient or caregiver variables, univariate logistic regression analyses (EE and rearing style) and twosided Pearson's correlations (perceived criticism) were specified. Associations at $p<0.10$ are displayed to avoid type II error, and findings at $p<0.05$ are mentioned and interpreted in the text. As the sample size of this pilot study is low, no correction for multiple testing was applied, no multivariate analyses were performed, and $p$ values are interpreted descriptively. Besides significance level, effect size was chosen as the main statistical descriptor, that is, odds ratios in regression analyses and as $r$ in correlational analyses. Analyses were performed using SPSS version 20 (IBM Corp).

TABLE 1. Sample Description $(N=31)$

\begin{tabular}{lcr}
\hline & n/Mean & \%/SD \\
\hline Age, mean (SD), yrs & 15.8 & 1.0 \\
Sex, male & 23 & 74.2 \\
Attendance to secondary school & 18 & 58.1 \\
Living with one caregiver & 15 & 48.3 \\
Diagnostic distribution & & \\
Schizophrenia & 18 & 58.1 \\
Schizophreniform disorder & 7 & 22.5 \\
Schizoaffective disorder & 3 & 9.7 \\
Delusional disorder & 2 & 6.5 \\
Psychotic disorder not otherwise specified & 1 & 3.2 \\
Clinical variables at baseline & & \\
Comorbid substance abuse (n, \%) & 10 & 32.2 \\
DUI, median (first and third quartile), mos & 6 & $2-14$ \\
DUP, median (first and third quartile), mos & 2 & $1-5$ \\
DUN, median (first and third quartile), mos & 1 & $1-12$ \\
CGI, severity of illness & 5.1 & 1.3 \\
PANSS, total score & 86.1 & 21.7 \\
PANSS, positive symptoms score & 22.2 & 6.0 \\
PANSS, negative symptoms score & 19.9 & 7.1 \\
CBCL, externalizing $t$ scores & 58.5 & 9.8 \\
CBCL, internalizing $t$ scores & 69.4 & 9.1 \\
Premorbid adjustment, childhood & 0.29 & 0.13 \\
Premorbid adjustment, adolescence & 0.38 & 0.14 \\
\hline
\end{tabular}

CBCL, Child Behavior Checklist; DUP, duration of untreated psychosis; DUI, duration of untreated illness; DUN, duration of untreated negative symptoms; PAS, premorbid adjustment scale; PANSS, positive and negative symptom scale; mos, months. 


\section{RESULTS}

\section{Sample}

Sample characteristics are provided in Table 1. Most patients received a diagnosis of schizophrenia or schizophreniform disorder. Patients were severely ill, as indicated by high CGI-S and PANSS ratings. Because of the small sample size, no between-site comparisons were possible. However, no differences in any baseline variables were detected between participating countries.

\section{EE Status, Perceived Criticism, and Parenting Style}

The distribution of EE status, perceived criticism, and rearing styles as measured by the PBI is provided in Table 2. No associations between EE subdomains, perceived criticism, and PBI subscales were detected.

\section{Correlates of EE Status}

As displayed in Table 3, there were no significant correlates of families' EE status.

\section{Correlates of Perceived Criticism}

Patient level of perceived criticism was significantly associated with an overall poorer quality of life $(r=-0.43)$ and, specifically, with poorer interactions with family $(r=-0.47)$ and peers $(r=-0.48$, all ps $<0.05)$.

\section{Correlates of Parenting Style}

Patients who perceived an adverse rearing style had a significantly lower rate of comorbid substance use and reported a worse overall illness concept (see Table 4). Optimal parenting was significantly associated with greater trust in the treating physician, a better overall illness concept, and a higher likelihood of lifetime substance use of the adolescent.

\section{DISCUSSION}

To the authors' knowledge, this is the first study exploring patient and family correlates of caregiver EE, perceived criticism, and rearing style in adolescents with EOS.

\section{Key Findings}

With $41 \%$ of families rated as HEE, the results are consistent with studies by Ramsauer et al., who found HEE in $53 \%$ of affected

TABLE 2. EE Status, Perceived Criticism, and Parenting Style

\begin{tabular}{lcc}
\hline & $\boldsymbol{N}$ & $\%$ \\
\hline EE status & & \\
$\quad$ Family rated HEE & 12 & 41.4 \\
At least one caregiver, high criticism & 4 & 13.8 \\
At least one caregiver, EOI & 10 & 34.5 \\
Perceived criticism & & \\
Mother perceived as critical & 11 & 37.9 \\
Father perceived as critical & 9 & 34.6 \\
At least one caregiver perceived as & 16 & 55.2 \\
$\quad$ critical & & \\
Parenting style & 10 & 37.0 \\
Optimal parenting, both caregivers & 8 & 29.6 \\
Affectionless control, one caregiver & Mother & Father \\
& 12 & 13 \\
Optimal parenting, $n$ & 3 & 5 \\
Affectionless control, $n$ & & \\
\hline
\end{tabular}

TABLE 3. Correlates of HEE Status and EOI

\begin{tabular}{|c|c|c|c|c|}
\hline & \multicolumn{4}{|c|}{ Model } \\
\hline & OR & \multicolumn{2}{|c|}{$95 \%$ CI } & $p$ \\
\hline \multicolumn{5}{|l|}{ Correlates of HEE } \\
\hline $\begin{array}{l}\text { Perceived guilt patient } \\
\text { (ICS) }\end{array}$ & 0.71 & 0.49 & 1.04 & 0.08 \\
\hline $\begin{array}{l}\text { Lack of support/acceptance } \\
\text { caregiver }\end{array}$ & 2.46 & 0.86 & 7.01 & 0.09 \\
\hline \multicolumn{5}{|l|}{ Correlates of EOI } \\
\hline Female sex & 5.33 & 0.93 & 30.64 & 0.06 \\
\hline $\begin{array}{l}\text { Global score, quality of life } \\
\text { (ILK) }\end{array}$ & 2.12 & 0.92 & 4.92 & 0.08 \\
\hline $\begin{array}{l}\text { Disorganized symptoms at } \\
\text { service entry (PANSS) }\end{array}$ & 1.21 & 0.99 & 1.47 & 0.06 \\
\hline $\begin{array}{l}\text { Negative expectations, } \\
\text { patient (ICS) }\end{array}$ & 0.84 & 0.68 & 1.03 & 0.10 \\
\hline $\begin{array}{l}\text { Global scores, highest } \\
\quad \text { functioning level (PAS) }\end{array}$ & 0.33 & 0.17 & 0.97 & 0.05 \\
\hline
\end{tabular}

ICS, Illness Concept Scale; HPI, Hamburg Personality Inventory; HEE, high expressed emotion; ILK, inventory of children's quality of life; PAS, premorbid adjustement scale; PANSS, positive and negative symptom scale.

families compared with $23.5 \%$ of control families, and Jarbin and colleagues, who found HEE in $41 \%$ of affected families (Jarbin et al., 2000; Ramsauer et al., 2013). Previous studies have found the prevalence of HEE in control groups to be considerably lower (between $0 \%$ and $38 \%$ ), indicating a potentially more adverse climate in affected families (Schimmelmann et al., 2003). However, the rate of "highly critical" caregivers $(13.8 \%)$ in this study seems low. Studies of adults experiencing their first episode of psychosis found rates of highly critical caregivers between 16.8\% (Heikkila et al., 2002) and 33\% (Raune et al., 2004). Moreover, previous findings point toward criticism being less prevalent in younger caregivers and in first-episode adult patients (Marom et al., 2005). The finding also may be related to the more restrictive approach of the FMSS in detecting criticism compared with the Camberwell Family Interview, which has been used in some studies of adults (Hooley and Parker, 2006).

High perceived criticism was much more prevalent than high criticism as measured by the FMSS. Consistent with previous research, no correlation was found between high criticism and perceived criticism (Bachmann et al., 2006; Medina-Pradas et al., 2013). Yet, perceived criticism was significantly associated with a lower quality of life in interaction not only with family but also with peers, which is in line with the finding that perceived criticism in adults with schizophrenia was associated with lower social functioning (Onwumere et al., 2009). Notably, quality of life is an important outcome parameter in schizophrenia (Lambert et al., 2003). Thus, high perceived criticism may be a good marker of patients and families in need of support, warranting further research.

Concerning perceived rearing style, patient perception of optimal parenting was associated with more favorable illness concept, whereas perceptions of adverse parenting were related to less favorable illness concept, particularly with regard to patient trust in their physician. This is of high clinical relevance, as negative illness concept has been linked to lower adherence to medication, whereas trust in the treating physician and in medication has been linked to better adherence (Conus et al., 2010; Kleindienst and Greil, 2004; Linden and Godemann, 2007; Schmidt et al., 2014). Research on adolescents with attention deficit/hyperactivity disorder similarly found that adverse rearing style was directly linked to poorer medication adherence (Gau et al., 2006). 
TABLE 4. Correlates of Optimal and Adverse Rearing

\begin{tabular}{|c|c|c|c|c|}
\hline \multirow{3}{*}{ Correlates of optimal rearing } & \multicolumn{4}{|c|}{ Model } \\
\hline & \multirow[t]{2}{*}{ OR } & \multicolumn{2}{|c|}{$95 \%$ CI } & \multirow{2}{*}{$p$} \\
\hline & & & & \\
\hline Substance abuse lifetime & 8.17 & 1.42 & 47.0 & 0.02 \\
\hline DUN & 0.16 & 0.02 & 1.2 & 0.08 \\
\hline DUI & 0.15 & 0.02 & 1.23 & 0.08 \\
\hline Sex, female & 5.00 & 0.87 & 28.9 & 0.07 \\
\hline Age of patient at entrance & 0.46 & 0.19 & 1.14 & 0.09 \\
\hline $\begin{array}{l}\text { Trust in physician, patient } \\
\text { (ICS) }\end{array}$ & 2.29 & 1.21 & 4.34 & 0.01 \\
\hline $\begin{array}{l}\text { Cumulative value of illness } \\
\text { concept, patient }\end{array}$ & 1.15 & 1.01 & 1.31 & 0.03 \\
\hline $\begin{array}{l}\text { Delinquent behavior, patient } \\
\text { (CBCL) }\end{array}$ & 0.76 & 0.57 & 1.03 & 0.08 \\
\hline $\begin{array}{l}\text { QoL patient, interaction with } \\
\text { family }\end{array}$ & 2.41 & 0.86 & 6.75 & 0.09 \\
\hline Neuroticism, mother (HPI) & 0.62 & 0.39 & 0.99 & 0.05 \\
\hline Extraversion, mother (HPI) & 1.70 & 1.00 & 2.93 & 0.06 \\
\hline $\begin{array}{l}\text { Trust in physicians, mother } \\
\text { (ICS) }\end{array}$ & 1.68 & 1.01 & 2.78 & 0.05 \\
\hline $\begin{array}{l}\text { Chance health expectations, } \\
\text { mother (ICS) }\end{array}$ & 1.25 & 1.00 & 1.57 & 0.05 \\
\hline $\begin{array}{l}\text { Illness concept total score, } \\
\text { mother }\end{array}$ & 1.10 & 1.00 & 1.20 & 0.06 \\
\hline \multicolumn{5}{|l|}{ Correlates of adverse rearing } \\
\hline Substance abuse comorbid & 0.15 & 0.03 & 0.91 & 0.04 \\
\hline $\begin{array}{l}\text { Trust in medication, patient } \\
\text { (ICS) }\end{array}$ & 0.81 & 0.64 & 1.02 & 0.07 \\
\hline $\begin{array}{l}\text { Negative expectations, } \\
\text { patient (ICS) }\end{array}$ & 1.28 & 1.00 & 1.65 & 0.05 \\
\hline $\begin{array}{l}\text { Illness concept total score, } \\
\text { patient (ICS) }\end{array}$ & 0.83 & 0.71 & 0.97 & 0.02 \\
\hline
\end{tabular}

CBCL, Child Behavior Checklist; ICS, Illness Concept Scale; HPI, Hamburg Personality Inventory; ILK, inventory of children's quality of life.

\section{Strengths and Limitations}

Strengths of this study include the assessment of a broad variety of potential correlates with family variables that have been linked to relapse in schizophrenia. By assessing newly diagnosed adolescent patients within 2 weeks of admission to the service, the association of family variables and potential correlates was explored at the very onset of treatment, minimizing biases associated with illness chronicity and effects of diagnostic and therapeutic interventions. Limitations of the study are mainly linked to the small sample size. EOS is rare and difficult to study, especially within the first 2 weeks of treatment initiation. Therefore, some of the negative associations may be due to the high risk for type II error. In addition, because correcting for multiple tests was not performed, type I errors might affect the results. Furthermore, some of the associations detected may not be causal, but epiphenomena of a third variable, which was not assessed. Generalizability of the results may be limited by the mainly hospitalbased sample. The necessary multicenter study approach leads to possible problems in interrater reliability. However, the PANSS and EE measures had good interrater reliability, and an effort was made to minimize reliability problems through extensive rater training and monitoring.

\section{CONCLUSIONS}

This pilot study identified several important correlates of perceived criticism and rearing style. The findings suggest that high perceived criticism and adverse rearing style should be assessed in clinical practice and paid attention to in family interventions, independent of a potential causal link to worse outcome. This is important as the findings suggest that perceived criticism is linked to lower quality of life and an adverse rearing style is linked to negative expectations and lower trust in medication in adolescents with EOS.

\section{ACKNOWLEDGMENTS}

The authors thank all participating patients and physicians.

\section{DISCLOSURES}

This study was supported by an unrestricted grant to BGS by the Werner Otto Foundation, Hamburg, Germany. The Werner Otto Foundation had no role in designing the study, collecting and analyzing the data, or writing the manuscript.

The authors declare no conflict of interest.

\section{REFERENCES}

Achenbach T (1991) Manuar for child behavior checklist/4-18 and 1991 profile. Burlington, VT: Department of Psychiatry, University of Vermont.

Algon S, Yi J, Calkins ME, Kohler C, Borgmann-Winter KE (2012) Evaluation and treatment of children and adolescents with psychotic symptoms. Curr Psychiatry Rep. 14:101-110.

American Psychiatric Association (2000) The diagnostic and statistical manual of mental disorders (4th ed, text rev ed). Washington, DC: American Psychiatric Association.

Andresen B (2000) Six basic dimensions of personality and a seventh factor of generalized dysfunctional personality: A diathesis system covering all personality disorders. Neuropsychobiology. 41:5-23.

Bachmann S, Bottmer C, Jacob S, Schröder J (2006) Perceived criticism in schizophrenia: A comparison of instruments for the assessment of the patient's perspective and its relation to relatives' expressed emotion. Psychiatry Res. 142:167-175.

Bird V, Premkumar P, Kendall T, Whittington C, Mitchell J, Kuipers E (2010) Early intervention services, cognitive-behavioural therapy and family intervention in early psychosis: Systematic review. Br J Psychiatry. 197:350-356.

Bunk D, Eggers C, Klapal M (1999) Symptom dimensions in the course of childhoodonset schizophrenia. Eur Child Adolesc Psychiatry. 8(suppl 1):I29-I35

Butzlaff RL, Hooley JM (1998) Expressed emotion and psychiatric relapse: A metaanalysis. Arch Gen Psychiatry. 55:547-552.

Cannon-Spoor H, Potkin S, Wyatt R (1982) Measurement of premorbid adjustment in chronic schizophrenia. Schizophr Bull. 8:470-484.

Cechnicki A, Bielańska A, Hanuszkiewicz I, Daren A (2013) The predictive validity of expressed emotions (EE) in schizophrenia. A 20 -year prospective study. $J$ Psychiatr Res. 47:208-214.

Conus P, Lambert M, Cotton S, Bonsack C, McGorry PD, Schimmelmann BG (2010) Rate and predictors of service disengagement in an epidemiological first-episode psychosis cohort. Schizophr Res. 118:256-263.

Dilling H, Mombour W, Schmidt MH (Eds) (2013) Internationale Klassifikation psychischer Störungen: ICD-10 Kapitel V (F) Klinisch-diagnostische Leitlinien. Bern, Switzerland: Verlag Hans Huber.

Döpfner M, Melchers P, Fegert J, Lehmkuhl G, Lehmkuhl U, Schmeck K, Steinhausen H-C, Poustka F (1994) Deutschsprachige Konsensus-Versionen der Child Behavior Checklist (CBCL 4-18), der Teacher Report Form (TRF) und der Youth Self Report Form (YSR). Kindheit und Entwicklung. 3:54-59.

Fux L, Walger P, Schimmelmann BG, Schultze-Lutter F (2013) The Schizophrenia Proneness Instrument, Child and Youth version (SPI-CY): Practicability and discriminative validity. Schizophr Res. 146:69-78.

Gau SS, Shen HY, Chou MC, Tang CS, Chiu YN, Gau CS (2006) Determinants of adherence to methylphenidate and the impact of poor adherence on maternal and family measures. J Child Adolesc Psychopharmacol. 16:286-297. 
Gearing RE (2008) Evidence-based family psychoeducational interventions for children and adolescents with psychotic disorders. J Can Acad Child Adolesc Psychiatry. 17:2-11.

Guy W (1976) Clinical global impression: ECDEU Assessment Manual for Psychopharmacology, revised. Rockville, MD: National Institute of Mental Health.

Heikkila J, Karlsson H, Taiminen T, Lauerma H, Ilonen T, Leinonen KM, Wallenius E, Virtanen H, Heinimaa M, Koponen S, Jalo P, Kaljonen A, Salakangas RK (2002) Expressed emotion is not associated with disorder severity in first-episode mental disorder. Psychiatry Res. 111:155-165.

Hooley JM, Parker HA (2006) Measuring expressed emotion: An evaluation of the shortcuts. J Fam Psychol. 20:386-396.

Hooley JJM, Teasdale JJD (1989) Predictors of relapse in unipolar depressives: Expressed emotion, marital distress, and perceived criticism. J Abnorm Psychol. 98:229-235.

Jarbin H, Grawe RW, Kjell H (2000) Expressed emotion and prediction of relapse in adolecents with psychotic disorders. Nord J Psychiatry. 54:201-205.

Kay S, Opler L, Lindenmayer J (1987) Reliability and validity of the Positive and Negative Syndrome Scale for schizophrenics. Psychiatry Res. 23:99-110.

Kleindienst N, Greil W (2004) Are illness concepts a powerful predictor of adherence to prophylactic treatment in bipolar disorder? J Clin Psychiatry. 65:966-974.

Krauss H, Marwinski K, Schulze T, Mueller DJ, Held T, Rietschel M, Maier W, Freyberger HJ (2000) Reliability and validity of the German version of the Premorbid Adjustment Scale (PAS). Nervenarzt. 71:188-194.

Lambert M, Schimmelmann BG, Karow A, Naber D (2003) Subjective well-being and initial dysphoric reaction under antipsychotic drugs - Concepts, measurement and clinical relevance. Pharmacopsychiatry. 36(suppl 3):S181-S190.

Leeb B, Hahlweg K, Goldstein MJ, Feinstein E, Mueller U, Dose M, Magana-Amato A (1991) Cross-national reliability, concurrent validity, and stability of a brief method for assessing expressed emotion. Psychiatry Res. 39:25-31.

Linden M, Godemann F (2007) The differentiation between "lack of insight" and "dysfunctional health beliefs" in schizophrenia. Psychopathology. 40:236-241.

Linden M, Nather J, Wilms HU (1988) Definition, significance and measurement of disease concepts of patients. The Disease Concept Scale for schizophrenic patients. Fortschr Neurol Psychiatr. 56:35-43.

Linszen D, Dingemans P, Lenior M (2001) Early intervention and a five year follow up in young adults with a short duration of untreated psychosis: Ethical implications. Schizophr Res. 51:55-61.

Linszen D, Dingemans P, Van der Does JW, Nugter A, Scholte P, Lenior R, Goldstein MJ (1996) Treatment, expressed emotion and relapse in recent onset schizophrenic disorders. Psychol Med. 26:333-342.

Magana AB, Goldstein JM, Karno M, Miklowitz DJ, Jenkins J, Falloon IR (1986) A brief method for assessing expressed emotion in relatives of psychiatric patients. Psychiatry Res. 17:203-212.

Marom S, Munitz H, Jones PB, Weizman A, Hermesh H (2005) Expressed emotion: Relevance to rehospitalization in schizophrenia over 7 years. Schizophr Bull. 31:751-758.

Mattejat F, Jungmann J, Meusers M, Moik C, Schaff C, Schmidt MH, Scholz M, Remschmidt H (1998) Das inventar zur erfassung der lebensqualität bei kindern und jugendlichen (ILK)—Eine pilotstudie. Z Kinder Jugendpsychiatr. 26:174-182.

Medina-Pradas C, Navarro JB, Pousa E, Montero MI, Obiols JE (2013) Expressed and perceived criticism, family warmth, and symptoms in schizophrenia. Span $J$ Psychol. 16:1-8.
Meng H, Schimmelmann BG, Koch E, Bailey B, Parzer P, Gunter M, Mohler B, Kunz N, Schulte-Markwort M, Felder W, Zollinger R, Burgin D, Resch F (2009) Basic symptoms in the general population and in psychotic and non-psychotic psychiatric adolescents. Schizophr Res. 111:32-38.

Meng H, Schimmelmann BG, Mohler B, Lambert M, Branik E, Koch E, Karle M, Strauss M, Preuss U, Amsler F, Riedesser P, Resch F, Burgin D (2006) Pretreatment social functioning predicts 1 -year outcome in early onset psychosis. Acta Psychiatr Scand. 114:249-256.

Onwumere J, Bebbington P, Kuipers E (2011) Family interventions in early psychosis: Specificity and effectiveness. Epidemiol Psychiatr Sci. 20:113-119.

Onwumere J, Kuipers E, Bebbington P, Dunn G, Freeman D, Fowler D, Garety P (2009) Patient perceptions of caregiver criticism in psychosis: Links with patient and caregiver functioning. J Nerv Ment Dis. 197:85-91.

Parker G, Johnston P, Hayward L (1988) Prediction of schizophrenic relapse using the parental bonding instrument. Aust N Z J Psychiatry. 22:283-292.

Parker G, Tupling H, Brown LB (1979) A parental bonding instrument. Br J Med Psychol. 134:138-147.

Perkins DO, Leserman J, Jarskog LF, Graham K, Kazmer J, Lieberman JA (2000) Characterizing and dating the onset of symptoms in psychotic illness: The Symptom Onset in Schizophrenia (SOS) inventory. Schizophr Res. 44:1-10.

Pharoah F, Mari JJ, Rathbone J, Wong W (2010) Family intervention for schizophrenia. Cochrane Database Syst Rev. 12:CD000088.

Ramsauer B, Lotzin A, Parzer P, Resch F (2013) Head position and expressed emotion of adolescents with schizophrenia and their caregivers compared to non-patient controls. Psychopathology. 46:225-232.

Raune D, Kuipers E, Bebbington PE (2004) Expressed emotion at first-episode psychosis: Investigating a carer appraisal model. Br J Psychiatry. 184:321-326.

Schimmelmann BG, Conus P, Cotton S, McGorry PD, Lambert M (2007) Pre-treatment, baseline, and outcome differences between early-onset and adult-onset psychosis in an epidemiological cohort of 636 first-episode patients. Schizophr Res 95:1-8.

Schimmelmann BG, Meng H, Koch E, Karle M, Preuss U, Schulte-Markwort M (2003) Expressed emotion and the outcome of child and adolescent psychiatric disorders. Fortschr Neurol Psychiatr. 71:517-526.

Schimmelmann BG, Michel C, Schaffner N, Schultze-Lutter F (2011) What percentage of people in the general population satisfies the current clinical at-risk criteria of psychosis? Schizophr Res. 125:99-100.

Schimmelmann BG, Schmidt SJ, Carbon M, Correll CU (2013a) Treatment of adolescents with early-onset schizophrenia spectrum disorders: In search of a rational, evidence-informed approach. Curr Opin Psychiatry. 26:219-230.

Schimmelmann BG, Walger P, Schultze-Lutter F (2013b) The significance of at-risk symptoms for psychosis in children and adolescents. Can J Psychiatry. 58:32-40.

Schmidt SJ, Grunert VM, Schimmelmann BG, Schultze-Lutter F, Michel C (2014) Differences in coping, self-efficacy, and external control beliefs between patients at-risk for psychosis and patients with first-episode psychosis. Psychiatry Res. 30:95-102.

Stark FM, Buchkremer G (1992) The five-minute interview. A brief method for assessing expressed emotion status. Nervenarzt. 63:42-45.

Steinhausen H-C, Winkler Metzke C (2001) Die züricher lebensereignis-liste (ZLEL): Ergebnisse einer schweizer epidemiologischen untersuchung. Kindh Entwickl. $10: 47-55$. 